\title{
莡訨
}

energy innovation

\section{MICROMETEOROLOGICAL MEASUREMENT OF THE DRY DEPOSITION FLUXX OF SULPHATE AND NITRATE AEROSOLS TO CONIFEROUS FOREST}

\author{
G.P. WYERS \\ J.H. DUYZER
}




\title{
MICROMETEOROLOGICAL MEASUREMENT OF THE DRY DEPOSITION FLUXX OF SULPHATE AND NITRATE AEROSOLS TO CONIFEROUS FOREST
}

\author{
G.P. WYERS \\ J.H. DUYZER* \\ * TNO-ENVIRONMENTAL SCIENCES \\ P.O. BOX 6011,2600 GA DELFT, THE NETHERLANDS
}

"SUBMITTED FOR PUBLICATION IN ATMOSPHERIC ENVIRONMENT" 


\title{
Micrometeorological measurement of the dry deposition flux of sulphate and nitrate aerosols to coniferous forest
}

\author{
G.P. Wyers ${ }^{1)}$ and J.H. Duyzer ${ }^{2)}$ \\ 1) Netherlands Energy Research Foundation ECN \\ P.O. Box 1, 1755 ZG Petten, The Netherlands \\ ${ }^{2)}$ TNO-Environmental Sciences \\ P.O. Box 6011,2600 GA Delft, The Netherlands
}

\section{SUMMARY}

Dry deposition fluxes of sulphate and nitrate have been determined over a coniferous canopy using the aerodynamic gradient technique. Vertical concentration gradients of sulphate and nitrate were measured with filters; the gradient of ammonium(bi)sulphate was measured with thermodenuders.

Filter measurements of sulphate yielded a deposition velocity ranging from near-zero under stable atmospheric conditions to $0.04 \mathrm{~m} \mathrm{~s}^{-1}$ under unstable conditions. The average deposition velocity over 23 measurements was $0.007 \mathrm{~m} \mathrm{~s}^{-1}$. Values of similar magnitude were derived from concentration gradients of ammonium(bi)sulphate. This deposition velocity has a near-linear dependency on $\mathrm{u}_{*}$, and ranges from $<0.0008 \mathrm{~m} \mathrm{~s}^{-1}$ at $\mathrm{u}_{*}<0.1 \mathrm{~m}$ $\mathrm{s}^{-1}$ to $0.034 \mathrm{~m} \mathrm{~s}^{-1}$ at $\mathrm{u}_{*}$ between 0.7 and $1 \mathrm{~m} \mathrm{~s}^{-1}$ with an overall average of $0.011 \mathrm{~m} \mathrm{~s}^{-1}$. This $V_{d}$ exceeds values observed in previous micrometeorological studies over forests and is twice as high as the $V_{d}$ predicted from a parametrization which is currently used to estimate aerosol deposition in the Netherlands. The annual flux of sulphate to this site is estimated at $190 \mathrm{~mol} \mathrm{SO}_{4} \mathrm{ha}^{-1} \mathrm{a}^{-1}$, implying that sulphate aerosol contributes approximately $30 \%$ of the dry deposition of SOx.

For nitrate a number of measurements in the first series showed deposition velocities larger than the maximum theoretically possible when the temperature was above $20^{\circ} \mathrm{C}$. These observed high deposition velocities for nitrate are not caused by artifacts related to simple measurement errors. There are however strong indications in the data that there is an effect of shifts in the equilibrium between ammoniumnitrate aerosol and nitric acid and ammonia. The influence of equilibrium processes between gas phase $\mathrm{NH}_{3}$ and $\mathrm{HNO}_{3}$ and aerosol phase $\mathrm{NH}_{4} \mathrm{NO}_{3}$ was investigated. It appeared that these processes could very well explain the extraordinary large gradients of nitrate aerosol observed in some of the experiments. This effect would lead to overestimation of the deposition velocity. It is therefore concluded that the observed gradients should be used with caution to estimate the dry deposition velocity of nitrate. As the size distributions of nitrate and sulphate in The Netherlands are similar (bimodal with Mass Median Diameters of 0.6 and $4.5 \mu \mathrm{m}$ for the fine and coarse modes respectively) it can be assumed that their deposition velocities will be similar. Based on this assumption an annual nitrate flux to the forest of $270 \mathrm{~mol}$ $\mathrm{ha}^{-1} \mathrm{a}^{-1}$ is estimated. 


\section{INTRODUCTION}

The dry deposition of aerosols to forests in The Netherlands was estimated to contribute between 10 and 20 percent of the total atmospheric deposition of potential acids (van Aalst en Erisman, 1991). These estimates are based on measured air concentrations and inferred dry deposition velocities. No experimental evidence for the deposition velocities used was available. The uncertainty in these estimates is therefore high.

In the atmosphere the primary pollutant sulphur dioxide $\left(\mathrm{SO}_{2}\right)$ and the mainly secondary pollutant nitrogen dioxide $\left(\mathrm{NO}_{2}\right)$ are readily oxidised to sulphate $\left(\mathrm{SO}_{4}\right)$ and nitrate $\left(\mathrm{NO}_{3}\right)$. Whereas $\mathrm{NO}_{3}$ may be present in the gas phase as nitric acid vapour, $\mathrm{SO}_{4}$ is nearly exclusively found in the aerosol phase. At normal humidities $\mathrm{SO}_{4}$ and $\mathrm{NO}_{3}$ are commonly found in the submicron size range ie. 0.1 to $1 \mu \mathrm{m}$ diameter. According to Whitby (1978) 95 to $100 \%$ of continental sulphate aerosol is present in a size fraction with a mass median diameter of $0.5 \mu \mathrm{m}$ and a geometrical standard deviation of 2. Sulphate originating from sea spray might be much larger. Size distributions of aerosols have also been determined in The Netherlands with Andersen impactors during air pollution episodes in 1983 and 1984. The size distributions of sulphate and nitrate are bimodal and very similar. The fine fractions are characterized by a mass median diameter (MMD) of 0.6 and a $\sigma_{\mathrm{g}}$ of 2.2-2.3, the coarse fractions of sulphate and nitrate have an MMD of $4.5 \mu \mathrm{m}$ and a $\sigma_{\mathrm{g}}$ of 1.6. Approximately $15 \%$ of the mass of nitrate is found in the coarse mode (above $2 \mu \mathrm{m}$ ); for sulphate this is $11 \%$ (see Wyers et al., 1994 and Ruijgrok et al., 1994).

Wind tunnel experiments have shown that the dry deposition of aerosol is strongly dependent on particle size (Sehmel and Hodgson, 1980). The deposition of submicron aerosol to vegetative surfaces can be considered a two-stage process: turbulent transport through the surface layer followed by transport through the viscous sublayer surrounding vegetation elements. A number of processes is responsible for crossing this viscous sublayer. Brownian diffusion is most efficient for very small particles with diameters less than $0.1 \mu \mathrm{m}$. For larger particles near $1 \mu \mathrm{m}$ inertial impaction and interception become important deposition mechanisms. Furthermore, deposition can be augmented by phoretic processes or electrical forces. However, in the size range for anthropogenic sulphate $(0.1-1$ $\mu \mathrm{m})$ none of these processes are considered to be very efficient deposition mechanisms. Because wind tunnel studies indicated very small deposition velocities less than $1 \mathrm{~mm} \mathrm{~s}^{-1}$ for particles in the range $0.1-1 \mu \mathrm{m}$, the deposition of submicron aerosol has so far been considered relatively unimportant as compared to deposition of gaseous compounds.

However, capture of aerosols by conifers could be relatively efficient because of the shallow viscous sublayer developing over the conifer needles. Wiman (1988) suggests deposition velocities between 1 and $4 \mathrm{~mm} \mathrm{~s}^{-1}$. Several other models have been developed describing the relevant processes of aerosol deposition onto vegetation (Sehmel, 1980; Chamberlain, 1966; Slinn, 1982; Giorgi, 1986). Van Aalst (1986) discussed several of these models and showed that the model based estimates of the dry deposition velocity may differ by a factor of 10 . In a recent study by Peters and Eiden (1992) the diffusion of particles through the laminar sublayer surrounding needles was considered in more detail. This model was then applied using the characteristics of an existing spruce stand. This study showed that with windspeeds between 2 and $5 \mathrm{~m} / \mathrm{s}$ the deposition velocities of submicron particles are between 0.001 and $0.01 \mathrm{~m} \mathrm{~s}^{-1}$. 
The models mentioned above are largely based upon the results of windtunnel studies and have hardly been compared to field measurements. A very limited number of experiments has been performed over forest. Hicks et al (1982) report measurement over a pine plantation using an eddy correlation instrument measuring total sulphur. On occasions when no gaseous sulphur compounds were detected the measurements indicated deposition velocities for particulate sulphur that average about $0.007 \mathrm{~m} \mathrm{~s}^{-1}$ in daytime. Hicks et al. (1989) measured sulphate fluxes over a deciduous forest by eddy correlation. They found that $\mathrm{V}_{\mathrm{d}}$ ranged from virtually 0 at night to a maximum of $0.01 \mathrm{~m} \mathrm{~s}^{-1}$ at daytime with a long-term average value of $0.006 \mathrm{~m} \mathrm{~s}^{-1}$. Similar values are reported by Wesely et al. (1985) for a pine forest: the deposition velocity ranges from $0.009 \mathrm{~m} \mathrm{~s}^{-1}$ for moderately unstable conditions to 0.005 for a neutral atmosphere. Many field studies in forests using different methods such as artificial surfaces and canopy budgets have now been reported (Lindberg \& Lovett, 1985). These studies often imply larger deposition rates than the current theory predicts. This discrepancy has not yet been explained. Ruijgrok et al (1993) argue that these numbers should be treated with caution since there are many uncertainties in the interpretation of these measurements.

In 1993 several experiments were performed to estimate the deposition velocity of sulphate and nitrate aerosol over Speulderbos, a coniferous forest. The measurement site is described in detail by Erisman et al. (this volume). The aerodynamic gradient technique was used to measure the deposition fluxes of ammonium(bi)sulphate, of (total) sulphate and of nitrate aerosol. These experiments were part of an integrated study to assess the contribution of aerosol deposition to the total atmospheric input of acidifying and eutrophying compounds and base cations. This study was carried out within the framework of the Dutch Priority Programme on Acidification (third phase).

\section{METHODS}

\section{Concentration gradients of sulphate and nitrate}

The aerosol filter heads were mounted on $24.5,28.5,32.5$ and $34.5 \mathrm{~m}$ above the forest floor on $1.5 \mathrm{~m}$ long booms. In order to prevent flow distortion from the tower the filters were mounted on different corners of the mast depending on wind direction. Two hour samples were taken during most campaigns. The airflow through the filters was measured by electronic mass flow meters. These mass flow meters were calibrated simultaneously in a specific experiment aimed to minimize systematic errors in the calibration. Three filter sets at each level could be mounted simultaneously. During the day the filters were removed as soon as possible after sampling and stored in order to prevent contamination. During the night however filters would be exposed for several hours after sampling is stopped. Possible sampling errors due to passive sampling in these periods were examined. During 15 hours of exposure the filters collected 10 to $30 \%$ of the amount collected during active sampling. Since, during the day, filters were removed directly after sampling this should not present a large error. The first filters exposed at night could contain a fraction of passively collected material. In those cases a small error may occur when the atmospheric conditions during the period of passive collection differ strongly from those during active sampling. Ultrasonic extraction of the filters was performed in $7 \mathrm{ml}$ of double demineralised water. The nitrate and sulphate content of the extraction solution was determined by ion chromatography. 
In the first number of experiments Pallflex quartz filters were used. Filter blanks were high for sulphate with values equivalent to nearly $10 \mu \mathrm{g} \mathrm{m}^{-3}$. For nitrate blanc values were around $1 \mu \mathrm{g} \mathrm{m}^{-3}$. The Pallflex filters were replaced by Teflon filters in the second phase (runs 17-39) in order to decrease the blanc contribution. Using the Teflon filters the blanc values for sulphate were reduced considerably to only a few percent or $0.2 \mu \mathrm{g}$ per filter. Blanc values for nitrate were even lower. From measurements with all filters sampling at the same height it was concluded that the precision of this method allowed concentration gradients of around 2 percent to be detected. This leads to an uncertainty in the deposition velocity of the order of $0.005 \mathrm{~m} \mathrm{~s}^{-1}$. At night when the stable atmosphere can create stronger gradients the performance could be better. This sensitivity is low but will still allow a discrimination between the high deposition velocities derived from e.g. throughfall methods and values of $0.002-0.006 \mathrm{~m} \mathrm{~s}^{-1}$ as indicated by other methods.

\section{Concentration gradients of a mmonium(bi)sulphate}

The vertical concentration gradient of ammonium(bi)sulphate and sulphuric acid over the forest was measured by thermodenuders. Air is sampled for $30 \mathrm{~min}$ at a rate of 0.51 $\mathrm{min}^{-1}$ in two CuO-coated quartz tubes connected in series. The first tube is heated at $120^{\circ} \mathrm{C}$ to vaporize and sample sulphuric acid; ammonium(bi)sulphate is decomposed and the produced sulphuric acid sampled in the second tube which is heated at a temperature of $270^{\circ} \mathrm{C}$ (Slanina et al., 1985). In front of the heated denuders two tubes at ambient temperature were used for removal of $\mathrm{H}_{2} \mathrm{~S}$ and organo-S from the air stream to avoid interference with the determination of aerosol sulphate. After sampling, the $\mathrm{Cu}(\mathrm{II}) \mathrm{SO}_{4}$ formed on the coating of both tubes is thermally dissociated at a temperature of $800^{\circ} \mathrm{C}$ and the formed $\mathrm{SO}_{2}$ is led to a pulsed-fluorescence detector in a small flow of dinitrogen gas. For a sampling time of $30 \mathrm{~min}$ the detection limit is $0.05 \mu \mathrm{gSO}_{4} \mathrm{~m}^{-3}$. A complete cycle of sampling, heating and cooling lasts two hours. Before starting the measurements over the forest, three thermodenuders were run simultaneously in parallel mode for a period of two weeks to examine systematic and random errors in the determination. Systematic differences up to $6 \%$ were observed. The relative precision of the measurements was $4 \%$. This precision corresponds to an uncertainty in the deposition velocity of $0.01 \mathrm{~m} \mathrm{~s}^{-1}$ under neutral atmospheric conditions. The uncertainty will be less under more stable conditions when concentration gradients are larger. This high uncertainty is far from ideal but suffices for our purpose which is to determine if dry deposition of aerosol constitutes an important part of the total atmospheric input.

For measurement of vertical concentration gradients, three thermodenuders were placed on a scaffold at the site Speuld at heights of $22 \mathrm{~m}, 26 \mathrm{~m}$ and $34 \mathrm{~m}$ above the forest floor, corresponding with a height of 2-14 m above the top of the canopy. During the experiment measurements of the vertical concentration gradient were performed every two hours. All measurements were corrected for the detected bias on the basis of the intercomparison described above.

\section{Calculation of the flux}

Fluxes of momentum and sensible heat were measured with two sonic anemometers (Kayo Denki DAT 310 with TR61 probe) mounted at heights of 30 and $36 \mathrm{~m}$. For the calculation of the flux modified flux-profile relations were applied, which have been derived for this site from a comparison between heat fluxes directly measured by eddy correlation and calculated from temperature gradients (see Duyzer et al., 1992). A more recent study by 
Weststrate and Duyzer (1994) involving a comparison of eddy correlation measurements of fluxes of ozone and sensible heat with vertical profiles of ozone and temperature yielded similar results. The modification concerns a height-dependent correction factor $\alpha$, which ranges from 0.73 for $\mathrm{z}=22 \mathrm{~m}$ to 0.9 for $\mathrm{z}=34 \mathrm{~m}$. When this correction is made, fluxprofile functions can be applied to gradient measurements that are partly performed within the roughness layer over the forest. The flux is calculated from a least-squares fit in which the concentration is plotted as a function of the logarithm of the stability-corrected height.

For stable conditions $(\mathrm{L}>0)$ :

$$
F=\frac{\kappa u_{*} c(z)}{\alpha \ln \left(\frac{z-d}{z_{0}}\right)-\Psi_{H}\left(\frac{z-d}{L}\right)+\Psi_{H}\left(\frac{z_{0}}{L}\right)}
$$

For unstable conditions $(\mathrm{L}<0)$ :

$$
F=\frac{\kappa u_{*} c(z)}{\alpha\left[\ln \left(\frac{z-d}{z_{0}}\right)-\Psi_{H}\left(\frac{z-d}{L}\right)+\Psi_{H}\left(\frac{z_{0}}{L}\right)\right]}
$$

in which $\mathrm{F}$ is the flux, $\kappa$ the Von Karman constant, $\mathrm{u}_{*}$ the friction velocity, $c(z)$ the concentration at height $\mathrm{z}, \mathrm{z}_{0}$ the roughness length, $d$ the displacement (i.c. $15 \mathrm{~m}$ ), $\mathrm{L}$ the Monin-Obukhov lenght and $\Psi_{\mathrm{H}}(\mathrm{z} / \mathrm{L})$ the integrated flux-profile function for heat.

\section{RESULTS}

Filter measurements of nitrate and sulphate deposition

Filter measurements of sulphate and nitrate were carried out during several campaigns in April, June/July, September and November/December 1993. Campaigns would usually last for two days. During the field campaign in June/July measurements were carried out on three consecutive days.

In Table 1 the environmental conditions for all campaigns are reported. The air concentrations of sulphate and nitrate are normal. For example in 1989 the average concentration of nitrate and sulphate in aerosols observed at Speuld was 5.6 and $4.6 \mu \mathrm{g}$ $\mathrm{m}^{-3}$ (van Aalst and Erisman, 1991). Only in November high concentrations were observed for sulphate.

For sulphate the deposition velocity, displayed in Figure 1, shows a large variation with values often not significantly different from zero. The first 16 runs, in which quartz filters were used, suffer from high blank values. The measurements in the second half of the programme (runs 17-39) lead to a more consistent picture. When turbulence is intense $\left(\mathrm{V}_{\mathrm{d}, \max }\right.$ is high) the uncertainty in the deposition velocity is large. In a few cases $V_{d}$ is 
near the maximum possible value. In those cases the error however is quite large. Mostly $\mathrm{V}_{\mathrm{d}}$ is much lower than $\mathrm{V}_{\mathrm{d} \text {,max }}$. The average $\mathrm{V}_{\mathrm{d}}$ during runs $17-39$ is $0.007 \pm 0.013 \mathrm{~m} \mathrm{~s}^{-1}$ and ranges from near-zero values during stable consitions to $0.04 \mathrm{~m} \mathrm{~s}^{-1}$ during unstable atmospheric conditions. Values are often close to the detection limit.

For nitrate the first half of the series of measurements indicates extremely high deposition velocities, often higher than the maximum possible (fig. 2). Although the blank values for nitrate in the first 16 runs were also higher than in later experiments, they cannot explain the observed high deposition velocities. It is interesting to see that in the second half of the series the deposition velocities for nitrate and sulphate correlate very well. For that period the average deposition velocity of nitrate is $0.012 \pm 0.019 \mathrm{~m} \mathrm{~s}^{-1}$. The range in $\mathrm{V}_{\mathrm{d}}$ is similar to that for sulphate, with near-zero values for stable conditions and maximum values during unstable conditions around $0.05 \mathrm{~m} \mathrm{~s}^{-1}$.

\section{Thermodenuder measurements of ammonium(bi)sulphate deposition}

The vertical concentration gradient of ammonium(bi)sulphate was measured continuously in the period 17 May - 23 August 1993. The average concentration in that period was 4.8 $\pm 3.2 \mathrm{gSSO}_{4} \mathrm{~m}^{-3}$. A small but distinct diurnal variation was observed with highest concentrations around noon. A possible explanation for this observed pattern is that during the night the surface layer is depleted of sulphate by deposition; after sunrise the mixing layer builds up and concentrations increase by mixing with air richer in sulphate from higher levels. The sulphuric acid concentration was very low, mostly below $0.2 \mathrm{\mu gSO}_{4} \mathrm{~m}^{-3}$ and never exceeding $0.8 \mathrm{\mu gSO}_{4} \mathrm{~m}^{-3}$, indicating a very high degree of neutralization of sulphate by ammonia. Due to malfunctioning of part of the equipment the measurements collected before 23 July are less accurate than measurements performed thereafter. Therefore, only the measurements collected in the period 23 July - 23 August were used to calculate deposition velocities for sulphate aerosol. Deposition parameters derived for this period can then be applied to estimate the deposition of sulphate for the full period May-August.

A time series of the measured deposition velocity $\left(\mathrm{V}_{\mathrm{d}}\right)$ and the maximum possible deposition velocity $V_{d, \max }\left(1 / r_{a}\right)$ is shown in Figure 3 for the period 23 July - 23 August 1993. Despite the large scatter in $V_{d}$, a positive correlation can be observed with $V_{d, \max }$. At very high turbulence intensities sometimes negative deposition velocities are observed. Under those conditions the concentration gradient is very small, leading to large errors in the flux. Also shown is the surface deposition velocity $\left(\mathrm{V}_{\mathrm{ds}}\right)$ which is defined as $\left(V_{d}^{-1}-r_{a}\right)^{-1}$ (Wesely et al., 1985). $V_{d s}$ is of similar magnitude as $V_{d}$, but the variability in $\mathrm{V}_{\mathrm{ds}}$ is considerably larger.

As the uncertainty in the individual gradient measurements is high, all measurements were sorted on $\mathrm{u}_{*}$, and for each $\mathrm{u}_{*}$-range a 50-percentile and an average $\mathrm{V}_{\mathrm{d}}$ were calculated (Table 2). Selection criteria applied are sufficient homogeneous fetch and $u>1 \mathrm{~m} \mathrm{~s}^{-1}$, leaving 339 measurements. Furthermore, the fluxes have been corrected for storage errors, caused by changes in concentration with time (see Fowler and Duyzer, 1991). Both $\mathrm{V}_{\mathrm{d}}(50)$ and average $\mathrm{V}_{\mathrm{d}}$ display a positive correlation with $\mathrm{u}_{*}$-class, but the average is considerably larger than the 50-percentile of $\mathrm{V}_{\mathrm{d}}$, which is caused by a few extreme values. This is obvious from the large standard deviation which is mostly exceeding the value of the average deposition velocity. The true $\mathrm{V}_{\mathrm{d}}$ is therefore better approximated by the median than by the average. 
$\mathrm{V}_{\mathrm{ds}}(50)$ shows a sudden increase at a $\mathrm{u}_{*}$ near $0.4 \mathrm{~m} \mathrm{~s}^{-1}$ from very low values of 0.0005 $0.005 \mathrm{~m} \mathrm{~s}^{-1}$ to values near $0.018 \mathrm{~m} \mathrm{~s}^{-1}$. Such an increase could potentially be indicative of a transition from one deposition mechanism to another. However, the average $V_{d s}$ is highly variable and has a standard deviation several times its value. The $V_{d}(50)$ increases with increasing friction velocity (fig.4) and can be approximated by the power function:

$$
\mathrm{V}_{\mathrm{d}}(50)=0.0444 \mathrm{u}_{*}^{1.47} \quad \text { with } \mathrm{r}^{2}=0.988
$$

This near-linear relationship between deposition velocity and friction velocity is somewhat unexpected. When impaction is the only mechanism responsible for passing the viscous sub-layer, $V_{d}$ should increase much stronger than linearly with $u_{*}$ (Van Aalst, 1986). The observed near-linear relationship suggests that a combination of deposition mechanisms is responsible for this dependency on $\mathrm{u}_{*}$. Model calculations yielded an analogous near-linear relationship between $\mathrm{V}_{\mathrm{d}}$ and $\mathrm{u}_{*}$ (Ruijgrok et al., 1994), which support the validity of the derived relationship.

\section{DISCUSSION}

Both filter measurements and thermodenuder measurements yield high but similar values for the deposition velocity of aerosol sulphate. For particulate nitrate however deposition velocities are sometimes observed which are (by far) exceeding the maximum possible deposition velocity. It should therefore be investigated whether the aerodynamic gradient method is a valid tool to derive deposition velocities for sulphate and nitrate.

\section{Applicability of the aerodynamic gradient method to aerosol deposition \\ Deposition velocities for particles can be derived from vertical concentration gradients if the flux is constant with height or if corrections for flux divergence can be made and are sufficiently small. Flux divergence is caused by e.g. chemical reactions within the air column studied, by changes in concentration with time or by horizontal gradients leading to advection (Fowler and Duyzer, 1991). As mentioned above, sulphate aerosol is neutralized to a high degree by ammonia at this site (Wyers and Erisman, 1995). The rate of formation of ammonium(bi)sulphate will therefore be limited by the rate of production of sulphuric acid, which is at most a few percent per hour and will therefore not lead to significant flux divergence. For nitrate however the reversible formation of ammoniumnitrate by reaction of ammonia and nitric acid may under certain conditions lead to a significant flux divergence. This will be discussed in more detail below.}

Particle production has been observed over wet surfaces due to interaction of sulphuric acid with water vapour, leading to apparent upward fluxes of small particles $<0.05 \mu \mathrm{m}$ (Lee and Wesely, 1988). As little mass is present in these particles, it is unlikely that vertical concentration gradients will be affected by this process. Flux divergence due to horizontal advection is also considered of minor importance. Although the site Speuld is surrounded by sources of ammonia, advection of amonium(bi)sulphate will be limited by the already high degree of neutralization of sulphate and the low production rate of sulphuric acid, but this may affect the measured gradients of nitrate. Changes in concentration with time may lead to significant storage errors. Measurements made in a period with large $\delta c / \delta$ t are therefore corrected accordingly. 
Sedimentation fluxes may contribute to the atmospheric deposition without producing a vertical concentration gradient. Particle size distributions have not been measured during this experiment. The concentration-weighted average size distribution of sulphate and nitrate previously determined with Andersen impactors during air pollution episodes in 1983 and 1984 show that less than $11 \%-15 \%$ of the mass of (respectively) sulphate and nitrate is present above $2 \mu \mathrm{m}$ and less than $1 \%-2 \%$ is larger than $10 \mu \mathrm{m}$. The contribution of sedimentation to the deposition flux of sulphate and nitrate with these size distributions will be small. Transport through the surface layer will therefore occur largely through eddy diffusion.

It can be concluded that the aerodynamic gradient method is a valid technique to obtain an estimate of the deposition velocity of sulphate. For nitrate however, shifts in the ammoniumnitrate equilibrium should be taken into consideration.

\section{The deposition velocity of sulphates}

In Figure 5 the observed deposition velocities for sulphate are compared to deposition velocities calculated with expression [3] and with an adapted version of Slinn's (1982) model (Ruijgrok et al., 1994). Expression [3] is a site specific relationship between $V_{d}$ and $\mathrm{u}_{*}$; the model used by Ruijgrok et al. should in principle be applicable to all receptor surfaces with a high roughness length. Both parametrization [3] and the model yield similar values (fig. 5). A reasonable correlation is found between observed $V_{d}$ and calculated $\mathrm{V}_{\mathrm{d}}$ for values between 0 and $0.05 \mathrm{~m} \mathrm{~s}^{-1}$, but also large positive and negative values are observed up to $\pm 0.1 \mathrm{~m} \mathrm{~s}^{-1}$ which deviate strongly from the predicted behaviour and are very likely the result of erroneous concentration gradient measurements.

Equation [3] was used to calculate average flux and deposition velocity from measured $\mathrm{u}_{*}$ and $\mathrm{SO}_{4}$ concentration for the entire measurement period May-August 1993. This yielded an average deposition velocity of $0.0114 \pm 0.0089 \mathrm{~m} \mathrm{~s}^{-1}$ and an average flux of $-0.059 \pm$ $0.060 \mu \mathrm{gSO}_{4} \mathrm{~m}^{-2} \mathrm{~s}^{-1}$, corresponding to approximately $190 \mathrm{~mol} \mathrm{SO}_{4} \mathrm{ha}^{-1} \mathrm{a}^{-1}$. The standard deviations of the mean are $0.0003 \mathrm{~m} \mathrm{~s}^{-1}$ and $0.0002 \mu \mathrm{gSO}_{4} \mathrm{~m}^{-2} \mathrm{~s}^{-1}$ for respectively the deposition velocity and the flux.

Dry deposition of aerosol in The Netherlands is currently estimated using a parametrization derived by Erisman (1993), which calculates the deposition velocity as a function of friction velocity and atmospheric stability. Application of this parametrization to the measurement period May - August 1993 results in an average deposition velocity of $0.0062 \pm 0.0051 \mathrm{~m} \mathrm{~s}^{-1}$. The results from the present study indicate that dry deposition of sulphate on coniferous forest has thusfar been underestimated by approximately a factor two. According to the present study dry deposition of sulphate constitutes approximately $30 \%$ of the total dry deposition of sulphur at this site.

The deposition velocities observed for sulphate aerosol over this forest are much higher than deposition velocities for submicron particles predicted from wind tunnel studies and are also high when compared to results from previous field studies over forests. For a deciduous forest with a similar tree height and a LAI at $50 \%$ of its summer maximum, Hicks et al. (1989) found a long-term average deposition velocity of $0.006 \mathrm{~m} \mathrm{~s}^{-1}$ with $\mathrm{V}_{\mathrm{d}} / \mathrm{u}_{*}$ ranging from 0.001 at stable conditions to 0.02 for a moderately unstable atmosphere. The average wind speed however was low, only $2 \mathrm{~m} \mathrm{~s}^{-1}$. For the site Speuld 
an average of 0.03 is found for the ratio $V_{d} / u_{*}$ at an average wind speed of $3.4 \mathrm{~m} \mathrm{~s}^{-1}$ (for the period May - August 1993).

Size resolved gradient- and eddy correlation measurements were performed at the site Speulderbos during a short period in the Summer of 1993 (29 June - 1 July) using two ASASP-X probes (Gallagher et al., this volume). They found a minimum deposition velocity at a particle diameter of $0.2 \mu \mathrm{m}$, which is consistent with current theory on particle deposition mechanisms. The peak deposition velocity determined by eddy correlation for the size range $0.1-0.4 \mu \mathrm{m}$ was $0.005 \mathrm{~m} \mathrm{~s}^{-1}$. The bulk deposition velocity determined by the aerodynamic gradient technique was a factor 5-6 larger than $V_{d}$ measured by eddy correlation, with maximum values around $0.03 \mathrm{~m} \mathrm{~s}^{-1}$. Further studies on this data set should make clear whether this difference in $\mathrm{V}_{\mathrm{d}}$ merely reflects the different size ranges observed, or is caused by other factors.

The natural radio-isotope ${ }^{214} \mathrm{~Pb}$, which is attached to aerosol particles, can be used as a tracer for fine aerosol deposition. Wyers and Veltkamp (this volume) found for this isotope at the site Speulderbos an average deposition velocity of $0.0073 \pm 0.0049 \mathrm{~m} \mathrm{~s}^{-1}$ with a standard deviation of the mean of $0.0010 \mathrm{~m} \mathrm{~s}^{-1}$. This somewhat lower deposition velocity for ${ }^{214} \mathrm{~Pb}$ is representative for a size distribution with an activity median diameter of $0.4 \mu \mathrm{m}$ and a geometric standard deviation of 3 .

The deposition velocity is strongly dependent on particle size distribution, and it is possible that a few large particles lead to the high values observed in this study. However, the size distributions for antropogenic sulphate show that little mass is present as supermicron particles. A second point worth mentioning is the very dense canopy of this forest. To avoid interference with the measurements, thinning of this forest was postponed, and the one-sided LAI now amounts to approximately 11 (Jans and Steingröver, pers. comm.). The canopy may therefore have become a very efficient receptor surface for fine aerosol. A third possible reason for the high observed deposition velocities is hygroscopic growth of the particles in the humidity gradient above the surface. Growth is under most conditions very fast compared to vertical transport times (Khlystov et al., 1993) and may shift the size distribution near the receptor surface to particle diameters which deposit very efficiently.

\section{The deposition velocity of nitrates}

It is difficult to understand the large deposition velocities observed for nitrates in the fist half of the programme. In the second half of the programme there is a close correspondence between deposition velocities for sulphate and nitrate (figs. 1 and 2) and such extreme values are no longer observed. During the first 16 experiments, when quartz filters were used, the nitrate blanks were much higher than in the second half of the study, when Teflon filters were used. However, the observed high deposition velocities in June and July that are sometimes exceeding $\mathrm{V}_{\mathrm{d} \text {,max }}$ are not simply the result of a high measurement uncertainty. These measurements coincide with an elevated ambient temperature above $20^{\circ} \mathrm{C}$. Several artefacts may have caused these observed high deposition velocities.

In principle gases could also be absorbed by the filters. This is especially the case for reactive gases such as nitric acid. Nitric acid is assumed to deposit efficiently to natural 
surfaces at a rate limited only by the aerodynamic resistance (Huebert and Robert, 1985, Meixner et al., 1988) and will therefore have a strong vertical gradient. If a significant amount of nitric acid is collected on each of the filters, a gradient in nitrate will be observed. Our calculations show however that the deposition flux of nitric acid is only a small fraction of the flux of aerosol nitrate. Nitrogen dioxide could also be captured on the filters, especilally when the filters are wet, but in several studies over the Speulderbos it was found that the $\mathrm{NO}_{2}$ flux is directed upward as if $\mathrm{NO}_{2}$ is emitted from the forest rather than deposited (Duyzer, 1994; Duyzer et al., 1994). Artifacts caused by capture of nitric acid and nitrogen dioxide therefore cannot explain the extremely high deposition velocities found for nitrate aerosol.

The evaporation of nitrate aerosols collected on filters could also play a role. The equilibrium constant of ammoniumnitrate is strongly dependent on relative humidity and temperature (Allen et al, 1989). Therefore gradients in temperature and/or humidity could lead to a vertical gradient in the extent to which ammoniumnitrate is evaporated from the filters. In view of the relatively short sampling periods the effect is probably quite small.

Whereas the other explanations for the observed high deposition velocities of nitrate are not very likely, equilibrium processes between aerosol phase and gas phase seem more important. Huebert et al. (1988) also observed anomalous vertical profiles of nitric acid vapour and nitrate aerosol. The gradients they observed were very different from the ones observed at other sites. The authors suggest that this difference is related to the high $\mathrm{NH}_{3}$ concentration, caused by emissions of a nearby cattle feedlot at this site. The aerosol gradients were in many cases steeper than those of nitric acid vapour. They found their results consistent with model calculations in which evaporation of $\mathrm{NH}_{4} \mathrm{NO}_{3}$ aerosol is combined with rapid deposition of $\mathrm{HNO}_{3}$ (Brost et al, 1988). Our findings could have been caused by the same phenomena. The influence of ammoniumnitrate on vertical gradients of nitrate and ammonia is discussed in detail elsewhere (Duyzer et al., 1995) and only a summary of their findings will be given here.

The deposition of $\mathrm{NH}_{3}$ and $\mathrm{HNO}_{3}$ could lead to low concentrations of these gases near the forest canopy. Moreover the temperature of the air close to the canopy is higher than aloft. Both effects could lead to a shift in the equilibrium between gas phase $\mathrm{NH}_{3}$ and $\mathrm{HNO}_{3}$ and $\mathrm{NH}_{4} \mathrm{NO}_{3}$ in the aerosol phase. When the air temperature near the canopy is higher than aloft (as would be important during the measurements in the summer) $\mathrm{NH}_{4} \mathrm{NO}_{3}$ will evaporate near the forest canopy. This causes a gradient in the nitrate aerosol concentration which leads to an overestimation of the deposition velocity. An important uncertainty in this mechanism is the evaporation rate of nitrate aerosols. According to Brost et al (1988) the uncertainty in the time constant by which an equilibrium between gas- and aerosol phase is established is a few orders of magnitude and lies between less than $1 \mathrm{~s}$ and $100 \mathrm{~s}$. Whether this shift in equilibrium therefore is really fast enough to interfere with the intensive turbulent exchange with time constants of $\mathrm{z} / \mathrm{Ku}_{*}$ (or around 25 s) remains uncertain. Other explanations for the current results are not available however. The importance of this mechanism is suggested by the strong correlation between the deposition velocity of nitrate aerosol and air temperature. For sulphate such a strong influence is not observed. It has to be realized that there is a similar correlation between air temperature and turbulence intensity which might also cause such cross-correlations. 
Nevertheless the data are in line with the influence of these equilibrium processes. High air temperatures would play a role via two processes. First, the equilibrium between gas and aerosol phase will shift towards the gas phase leading a downward gradient of ammoniumnitrate during the day. Second, the evaporation rate of ammoniumnitrate will increase. A higher evaporation rate will increase the importance of equilibrium processes relative to turbulent mixing.

During the measurement campaigns the vertical concentration gradient of ammonia above the forest was measured continuously by ECN (Wyers and Erisman, 1995). In the period 29 June - 1 July, when the temperature during the day was above $20^{\circ} \mathrm{C}$, high deposition velocities of nitrate coincide with observed (apparent) emissions of ammonia. In figure 6 the observed concentration gradients are plotted for nitrate and ammonia. Furthermore the temperature effect on the nitrate gradient is shown. The evaporation of ammoniumnitrate leads to an increase of the nitrate gradient higher than allowed by aerodynamic resistance and at the same time to a reversal of the $\mathrm{NH}_{3}$ concentration gradient. Both observations suggest that evaporation of ammoniumnitrate aerosol is responsible for the observed high deposition velocities of nitrate. These observations furthermore suggest that concentration gradients of $\mathrm{NH}_{3}$ at high temperatures $\left(>20^{\circ} \mathrm{C}\right)$ may also be influenced by such equilibrium processes and have to be treated with care.

As the size distributions of nitrate and sulphate in The Netherlands are similar it can be assumed that their deposition velocities will be similar. Assuming that the depositon velocity for nitrate is also $0.011 \mathrm{~m} \mathrm{~s}^{-1}$ and that the average concentration of nitrate is 4.6 $\mu \mathrm{g} \mathrm{m}^{-3}$ (Van Aalst and Erisman, 1991), an annual flux to the forest of $270 \mathrm{~mol} \mathrm{ha}^{-1} \mathrm{a}^{-1}$ can be estimated.

\section{CONCLUSIONS}

Measurements of the deposition flux of nitrate and sulphate aerosol were carried out over the Speulderbos. Concentration gradients of sulphate and nitrate were measured with filters; the concentration gradient of ammonium(bi)sulphate was measured with thermodenuders.

The filter measurements yielded an average deposition velocity for sulphate of $0.007 \mathrm{~m} \mathrm{~s}^{-1}$ $(\mathrm{N}=23) . \mathrm{V}_{\mathrm{d}}$ ranges from near-zero under stable atmospheric conditions to a maximum value of approximately $0.04 \mathrm{~m} \mathrm{~s}^{-1}$ under unstable conditions. Deposition velocities for ammonium(bi)sulphate aerosol are of similar magnitude and show a positive correlation with the friction velocity. For different $u_{*}$-ranges the median deposition velocities were calculated. Deposition velocities range from $\leq 0.0008 \mathrm{~m} \mathrm{~s}^{-1}$ for $\mathrm{u}_{*}<0.10 \mathrm{~m} \mathrm{~s}^{-1}$ to $0.034 \mathrm{~m}$ $\mathrm{s}^{-1}$ for $\mathrm{u}_{*}$ between 0.70 and $1.0 \mathrm{~m} \mathrm{~s}^{-1}$. The median deposition velocity $\mathrm{V}_{\mathrm{d}}(50)$ shows a near-linear increase with $\mathrm{u}_{*}$. Using this relationship the average $\mathrm{V}_{\mathrm{d}}$ for the period May August 1993 is estimated at $0.011 \mathrm{~m} \mathrm{~s}^{-1}$. The deposition velocity for sulphate on coniferous forest has sofar been underestimated by a factor two. The annual flux of sulphate aerosol to this site is estimated at approximately $190 \mathrm{~mol} \mathrm{SO}_{4} \mathrm{ha}^{-1} \mathrm{a}^{-1}$.

Filter measurements for nitrate showed deposition velocities larger than the maximum theoretically possible when the temperature was above $20^{\circ} \mathrm{C}$. It was concluded that the 
observed high deposition velocities for nitrate are not caused by artifacts related to simple measurement errors. There are however strong indications that there is an effect of shifts in the equilibrium between ammoniumnitrate aerosol and nitric acid and ammonia. The high temperatures of the air near the canopy during the day could lead to an enhanced evaporation of nitrate aerosol near the canopy. This would lead to a low concentration of aerosol nitrate near the canopy and an apparent high deposition velocity of aerosol nitrate. Concurrent measurements of the ammonia gradient showed that the $\mathrm{NH}_{3}$ was higher near the canopy top than aloft which is also consistent with evaporation of ammonium nitrate aerosol near the canopy. Based on this information it is concluded that the equilibrium processes have at least partly caused the observed concentration-gradient of nitrate (and deposition velocities derived from them), which is larger than theoretically possible. These measurements therefore cannot be used without caution to estimate the deposition velocity of nitrate aerosol.

It can concluded from this study that the gradient method can be used to determine the deposition velocity for sulphate aerosols over forest provided that measurement conditions are optimised. For nitrate aerosols there may be considerable problems with the interpretation of measurement results. As nitrate and sulphate in The Netherlands have similar size distributions, their deposition velocities can be considered similar. The inferred nitrate flux to this forest amounts to $270 \mathrm{~mol} \mathrm{ha}^{-1} \mathrm{a}^{-1}$.

\section{Acknowledgements}

The authors wish to express their gratitude to Anita Wayers, Han Möls, Henk Verhagen and Hilbrand Weststrate for their help with the experiments. Arjan Hensen critically read an earlier version of this manuscript. The discussions with our collegues in the Project Group Aerosol Deposition have been very helpfull and are highly appreciated. This study was part of the Dutch Priority Programme on Acidification and the EUROTRAC-BIATEX programme. Funding of the BIATEX-programme of ECN by the Ministry of Housing, Spatial Planning and Environment and the Ministry of Economic Affairs is gratefully acknowledged. 


\section{REFERENCES}

Allen, A.G., Harrison, R.M. and Erisman, J.W. (1989) Field measurements of dissociation of ammoniumnitrate and ammoniumchloride aerosols. Atmospheric Environment 23, 1591-1599.

Andersen, H.V.and Hilbert, G. (1992) Measurements of $\mathrm{NH}_{3} / \mathrm{NH}_{4}{ }^{+}$and $\mathrm{HNO}_{3} / \mathrm{NO}_{3}$ by denuder and filter pack. In I Allegrini (ed.) Development of analytical techniques for atmospheric pollutants. Air Pollution Research report 41 pp. 213-227

Brost, R.A., Delany, A.C. and Huebert, B.J. ( 1988) Numerical Modelling of concentrations and fluxes of $\mathrm{HNO}_{3}, \mathrm{NH}_{3}$ and $\mathrm{NH}_{4} \mathrm{NO}_{3}$ near the surface. J. Geophysical Research, 93, D6, 7137-7152

Chamberlain, A.C. (1966) Transport of gases to and from grass and grass-like surfaces. Phil. Trans. Roy. Soc. Lond. A 290, 236-265

Duyzer, J.H., Verhagen, H.L.M., Weststrate, J.H. and Bosveld, F.C. (1992) Measurement of the dry deposition flux of $\mathrm{NH}_{3}$ onto coniferous forest. Environmental Pollution, 75, 313.

Duyzer, J.H., Weststrate, J.H., Diederen, H.S.M.A., Vermetten, A., Hofschreuder, P., Wyers, G.P., Bosveld, F.C. and Erisman, J.W. (1994) The deposition of acidifying compounds and ozone to the Speulderbos derived from gradient measurements in 1988 and 1989. TNO report R94/095, Delft

Duyzer (1994) Deposition of ozone and nitrogendioxide to European forest. TNO report R94/060, Delft.

Erisman, J.W. (1993) Acid Deposition to Nature Areas in The Netherlands: Part II. Throughfall Measurements Compared to Deposition Estimates, Water, Air \& Soil Poll., 71(1/2) 81-100.

Fowler, D. and Duyzer, J.H. (1989) Micrometeorological techniques for the measurement of trace gas exchange. In: M.O. Andreae and S.D. Schimel (Eds.) Exchange of trace gases between terrestrial ecosystems and the atmosphere. John Wiley and Sons Ltd., 189-207.

Giorgi, F. (1986) A particle dry deposition parameterisation scheme for use in tracer transport models. Journal of Geophysical Research 91, D9, 9794-9806

Grosjean, D (1982) The stability of particulate nitrate in the Los Angeles atmosphere. The Science of the Total Environment, 25, 263-275

Hicks, B.B., Baldocchi, D.D., Meyers, T.P., Hosker, R.P. Jr., Matt, D.R. (1987) A preliminary multiple resistance routine for deriving dry deposition velocities from measured quantities. Water, Air \& Soil Poll. 36, 311-330. 
Hicks, B.B., Matt, D.R., McMillen, R.T., Womack, J.D., Wesely, M.L., Hart, R.L., Cook, D.R., Lindberg, S.E., De Pena, R.G. and Thomson, D.W. (1989) A field investigation of sulfate fluxes to a deciduous forest. J.Geophys.Res. 94, 13003-13011.

Hicks, B.B., Wesely, M.L., Durham, J.L. and Brown, M.A. (1982) Some direct measurements of atmospheric sulfur fluxes over a pine plantation. Atmospheric Environment 12, 2899-2903.

Huebert, B.J., Luke, W.T., Delany, A.C. and Brost, R.A. (1988) Measurement of concentrations and dry surface fluxes of atmospheric Nitrates in the presence of Ammonia. J. Geophysical Research, 93, D6, 7127-7136

Huebert, B.J. and Robert, C.H. (1985) The dry deposition of nitric acid to grass. J. Geophysical Research, 90, D1 p 2085-2090

Khlystov, A., Ten Brink, H.M. and Wyers, G.P. (1993) Hygroscopic growth rates of aerosols at high relative humidity. Report ECN-C--93-011, ECN, Petten.

Lee, I.Y. and Wesely, M.L. (1989) Effects of surface wetness on the evolution and vertical transport of submicron particles. J.Appl.Meteorol. 28, 176-184.

Lindberg, S.E. and Lovett, G.M. (1985) Field measurements of particle dry deposition rates to foliage and inert surfaces in a forest canopy. Environmental Science and Technology, 19 pp. $238-244$

Meixner, F.X., Franken, H.H., Duyzer, J.H. and Van Aalst, R.M. (1988) Dry deposition of gaseous $\mathrm{HNO}_{3}$ to a pine forest. In $\mathrm{H}$. van Dop (ed.) Air Pollution Modelling and its Application, 6.Plenum Publishing Corporation, pp 23-35

Peters, K. and Eiden, R. (1992) Modelling the dry deposition velocity of aerosol particles to a spruce forest. Atmospheric Environment, 26A, 14, 2555-2564

Ruigrok, W., Tieben, H and Eisinga, P. (1994) The dry deposition of acidifying and alkaline particles on Douglas fir. KEMA Report 20159-KES 94-X, Arnhem.

Sehmel, G. (1980) Particle and gas dry deposition : A review. Atmospheric Environment, 14, 983-1011

Sehmel, G.A. and Hodgson, W.H. (1980) A model for predicting dry deposition of particles and gases to environmental surfaces. AIChE Symposium Series 76, 218-230.

Slanina, J., Schoonebeek, C.A.M., Klockow, D., and Niessner, R. (1985) Determination of sulphuric acid and ammonium sulphates by means of a computer-controlled thermodenuder system. Anal.Chem. 57, 1955-1960.

Slinn, W.G.N. (1982) Predictions for particle deposition to vegetative surfaces. Atmospheric Environment 16, 1785-1794. 
Van Aalst, R.M. (1986) Dry deposition of aerosol particles. In: S.D. Lee, T. Schneider, L.D. Grant and P.J. Verkerk (Eds.) Aerosols. Lewis Publ., Chelsea MI, 933-949.

Van Aalst, R.M. and Erisman, J.W. (1991) Atmospheric input fluxes. In : Acidification Research in the Netherlands, G.J. Heij and T. Schneider (editors), Elsevier, Amsterdam. 239-288

Wesely, M.L. (1970) Eddy correlation measurements in the atmospheric surface layer over agricultural crops. Ph.D.-thesis, University of Wisconsin.

Wesely, M.L., Cook, D.R., Hart, R.L. and Speer, R.E. (1985) Measurements and parametrization of particulate sulphur over grass. J.Geophys.Res. 90, 2131

Weststrate, H. and Duyzer, J.H. (1994) Evaluatie van de gradiëntmethode voor monitoring van depositie op Speuld op basis van metingen voor $\mathrm{O}_{3}$. Report MW-R 94/104, TNO, Delft.

Whitby, K.T. (1978) Physical characteristics of sulphur aerosols. Atmospheric Environment $12,135-160$.

Wiman, B.L.B. (1988) Aerosol capture by complex forest architecture. In: Verhoeven, J.T.A., Heil, G.W., \& Werger, M.J.A. (eds.) Vegetation Structure in relation to Carbon- and Nutrient economy, SPB Academic Publishing, The Hague, pp. 157-183.

Wyers, G.P., Veltkamp, A.C., Vermeulen, A.T., Geudebroek, M., Wayers, A. and Mols, J.J. (1994) Deposition of aerosol to coniferous forest. Report ECN-C--94-051, Netherlands Emergy Research Foundation.

Wyers, G.P. and Erisman, J.W. (1995) Dry deposition of ammonia to coniferous forest. Submitted to Atmsopheric Environment. 
Tables

Table 1. Average values of windspeed $(U)$ and air temperature $(T)$ during aerosol measurement campaigns in 1993. All information is given on the lowest level (21 meter). The average concentrations of sulphate and nitrate and their ranges are also given. The second column $(N)$ indicates the number given to each successful measurement run.

\begin{tabular}{llllll} 
Campaign & $\mathrm{N}$ & $\begin{array}{l}\mathrm{U} \\
\mathrm{m} \mathrm{s}^{-1}\end{array}$ & $\begin{array}{l}\mathrm{T} \\
{ }^{\circ} \mathrm{C}\end{array}$ & $\begin{array}{l}\mathrm{SO}_{4} \\
\mu \mathrm{g} \mathrm{m}^{-3}\end{array}$ & $\begin{array}{l}\mathrm{NO}_{3} \\
\mu \mathrm{g} \mathrm{m}^{-3}\end{array}$ \\
\hline & & & & & \\
April & $1-2$ & 3.5 & 19 & $8(6-10)$ & $11(8-13)$ \\
June & $4-16$ & 2.4 & 19 & $5(3-10)$ & $4(1-7)$ \\
Sep & $17-28$ & 3.1 & 18 & $7(4-10)$ & $8(2-13)$ \\
Nov & $29-39$ & 2.0 & -2 & $25(15-60)$ & $13(11-20)$
\end{tabular}

Table 2. Deposition velocities of ammonium(bi)sulphate for different $u_{*}$-ranges

\begin{tabular}{lllllll}
\hline $\begin{array}{l}\mathrm{u}_{*}-\mathrm{range} \\
\mathrm{m} \mathrm{s}^{-1}\end{array}$ & $\begin{array}{l}\overline{\mathrm{u}_{*}} \\
\mathrm{~m} \mathrm{~s}^{-1}\end{array}$ & $\begin{array}{l}\mathrm{V}_{\mathrm{d}} 50 \\
\mathrm{~m} \mathrm{~s}^{-1}\end{array}$ & $\begin{array}{l}\overline{\mathrm{V}}_{\mathrm{d}} \\
\mathrm{m} \mathrm{s}^{-1}\end{array}$ & $\begin{array}{l}\mathrm{s.d} \\
\mathrm{m} \mathrm{s}^{-1}\end{array}$ & $\begin{array}{l}\mathrm{V}_{\mathrm{ds}} 50 \\
\mathrm{~m} \mathrm{~s}^{-1}\end{array}$ & $\mathrm{n}$ \\
\hline & & & & & & \\
$0.0-0.1$ & 0.058 & 0.0008 & 0.0009 & 0.0012 & 0.0005 & 28 \\
$0.1-0.2$ & 0.153 & 0.0020 & 0.0049 & 0.0016 & 0.0010 & 64 \\
$0.2-0.3$ & 0.245 & 0.0058 & 0.0139 & 0.0437 & 0.0052 & 71 \\
$0.3-0.4$ & 0.348 & 0.0092 & 0.0300 & 0.0600 & 0.0025 & 50 \\
$0.4-0.5$ & 0.449 & 0.0178 & 0.0261 & 0.0349 & 0.0184 & 53 \\
$0.5-0.7$ & 0.610 & 0.0190 & 0.0306 & 0.0462 & 0.0180 & 42 \\
$0.7-1.0$ & 0.822 & 0.0344 & 0.0584 & 0.0827 & 0.0181 & 31 \\
all data & 0.357 & 0.0060 & 0.0216 & 0.0480 & 0.0043 & 339 \\
\hline
\end{tabular}


Figure 1. The deposition velocity of sulphate aerosol measured during all campaigns in 1993. $\mathrm{V}_{\mathrm{d}, \max }$ is calculated as $\mathrm{r}_{\mathrm{a}}^{-1}$.

Figure 2. The deposition velocity of nitrate aerosol measured during all campaigns in 1993. $\mathrm{V}_{\mathrm{d}, \max }$ is calculated as $\mathrm{r}_{\mathrm{a}}^{-1}$.

Figure 3. Time series of deposition velocity $\left(\mathrm{V}_{\mathrm{d}}\right)$, surface deposition velocity $\left(\mathrm{V}_{\mathrm{ds}}\right)$ and maximum deposition velocity $\left(\mathrm{V}_{\mathrm{d}, \mathrm{max}}\right)$ above the Speulder Forest, 23 July - 2 August 1993.

Figure 4. Median deposition velocity and median surface deposition velocity for ammonium(bi)sulphate at different $\mathrm{u}_{*}$-ranges as a function of average $\mathrm{u}_{*}$.

Figure 5. Comparison of observed deposition velocities with deposition velocities predicted using relationship [3] and a modified version of Slinn's (1982) model (Ruijgrok et al., 1994).

Figure 6. The development of the difference in concentrations between the $36 \mathrm{~m}$ level and the $23 \mathrm{~m}$ level for 29 June - 1 July 1993

- $\quad$ observed for $\mathrm{NO}_{3}$ in aerosol

- $\quad$ estimated for $\mathrm{NO}_{3}$-aerosol due to temperature differences between the two levels

- $\quad$ estimated for $\mathrm{HNO}_{3}$

- $\quad$ observed for $\mathrm{NH}_{3}$ 

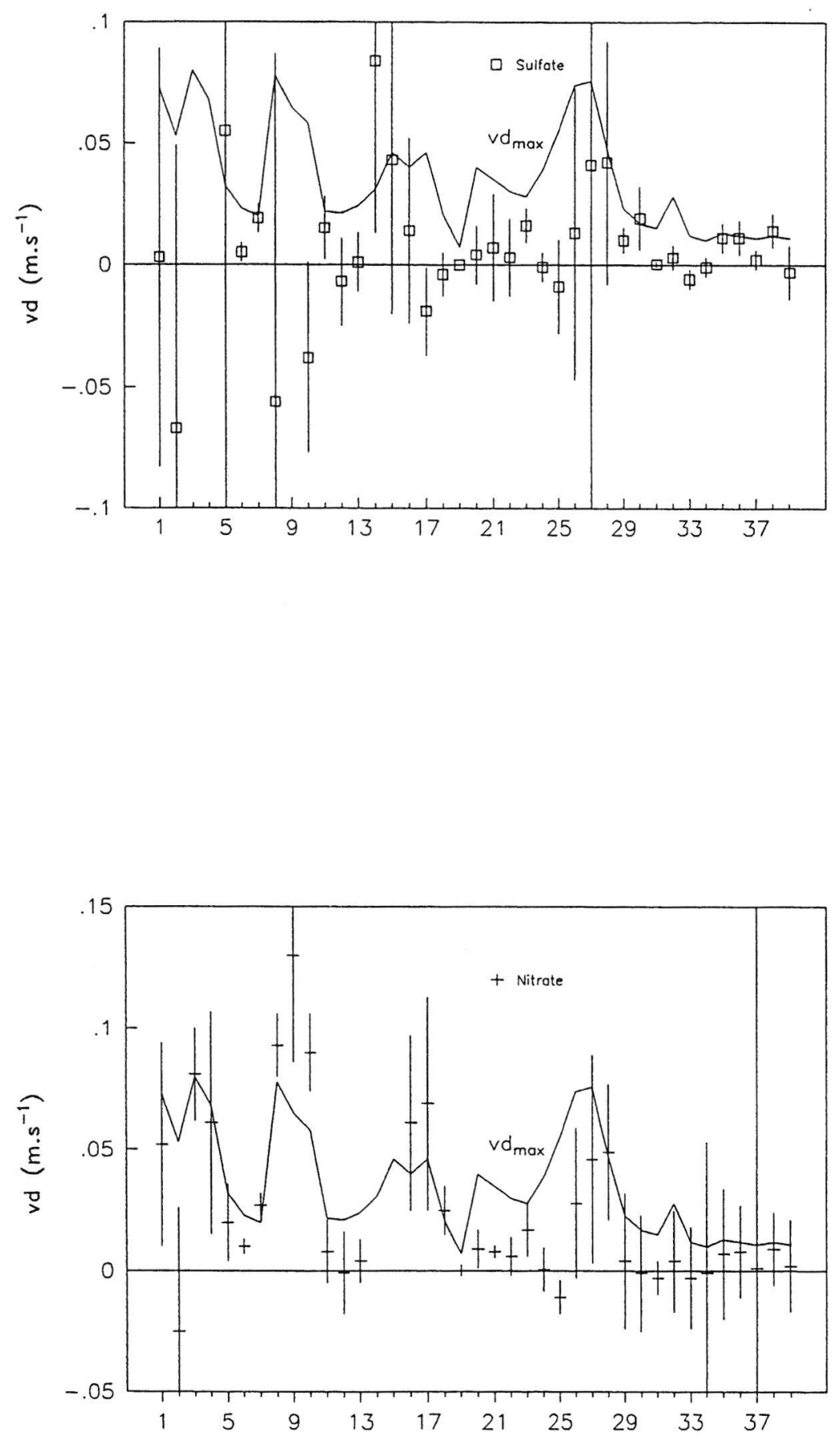


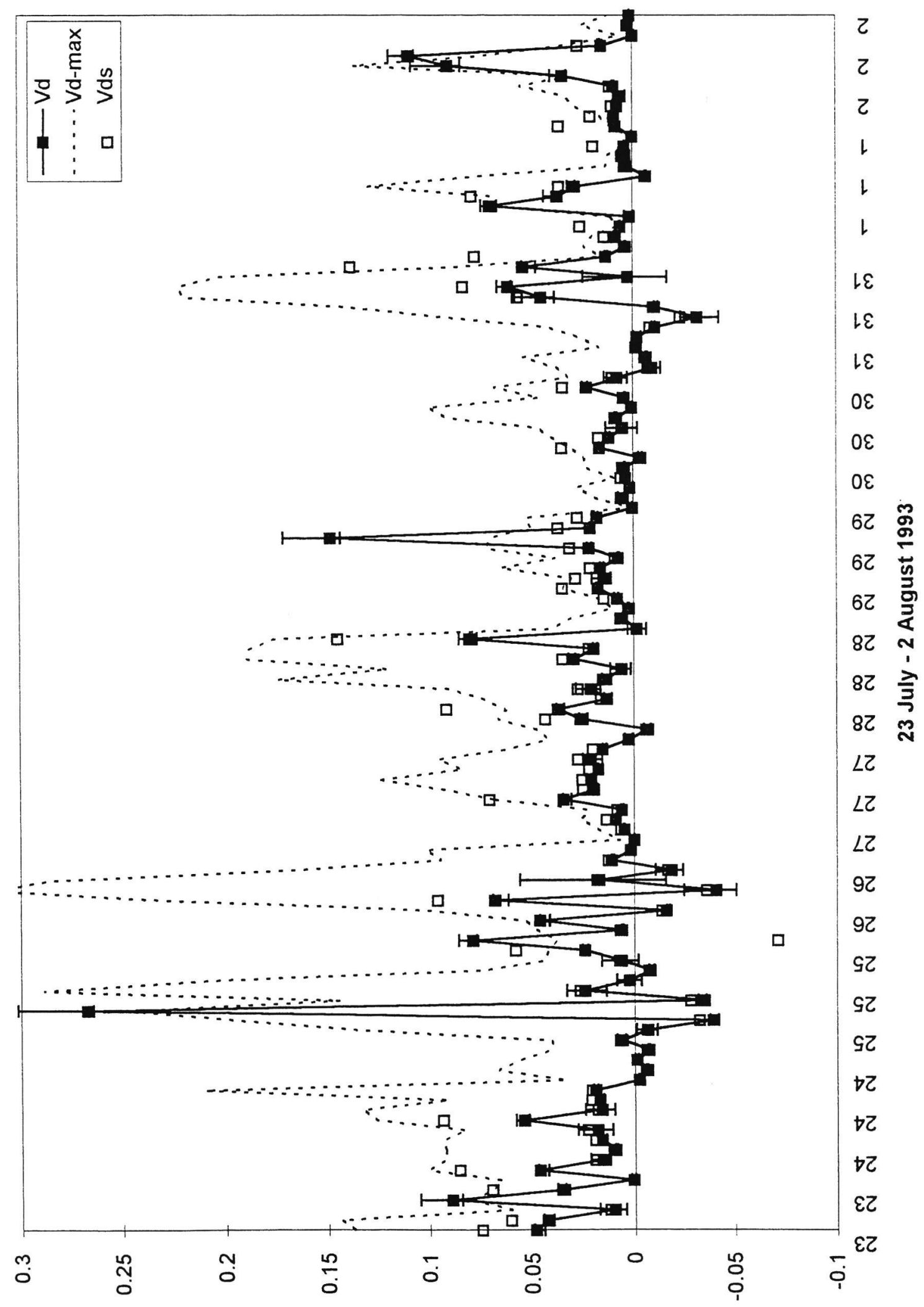

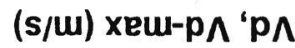




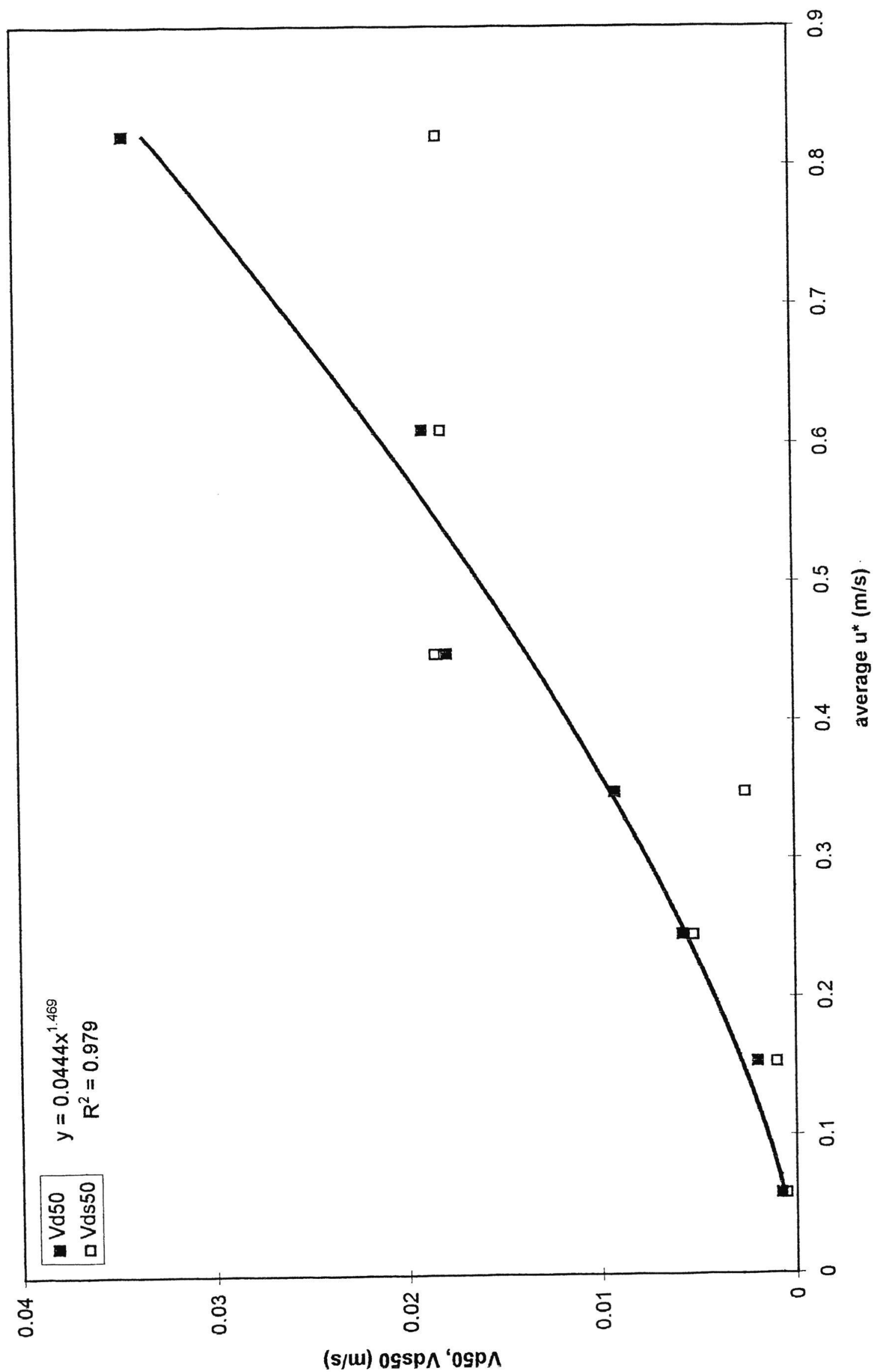




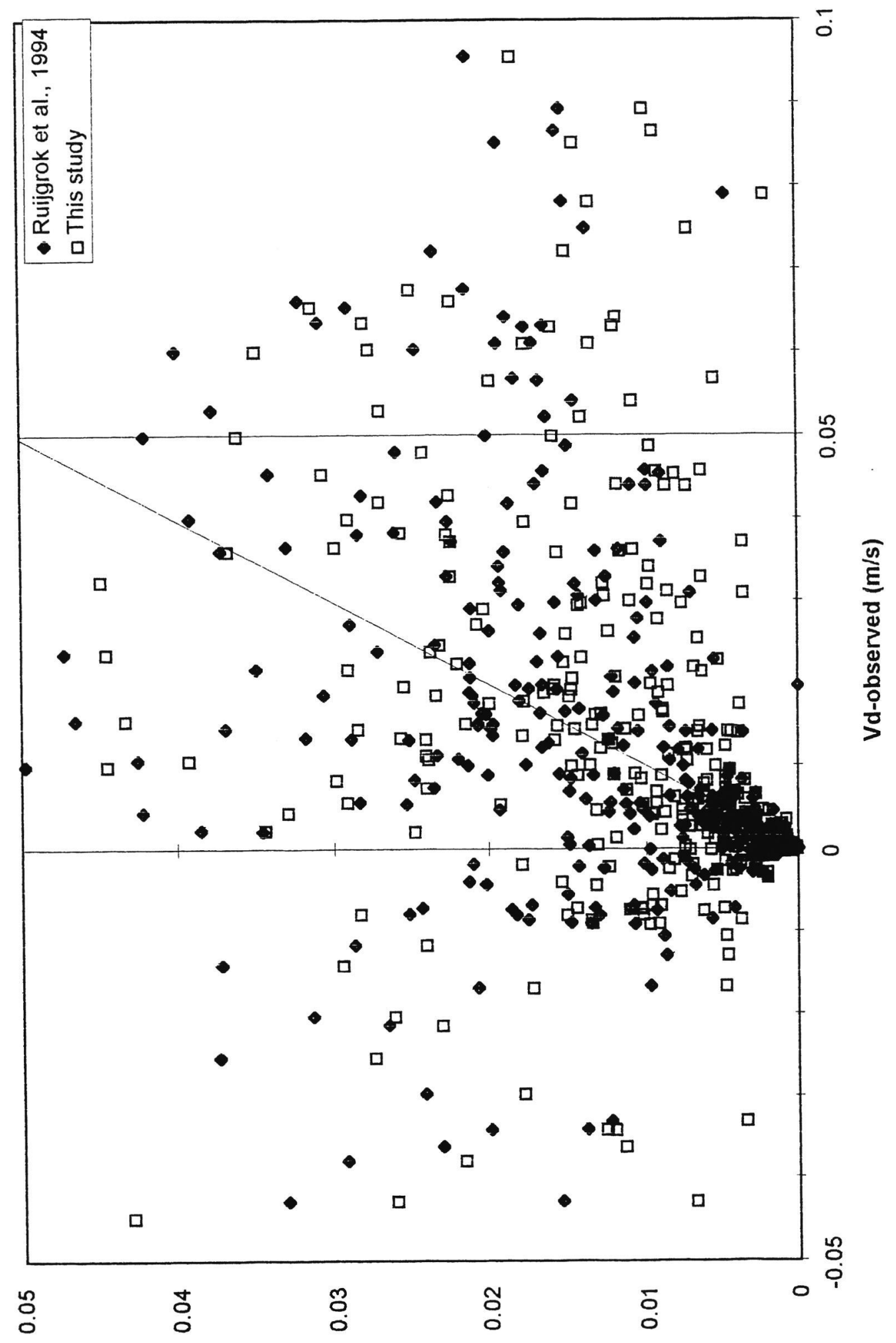

(s/u) pəz! 
29 june - 1 july

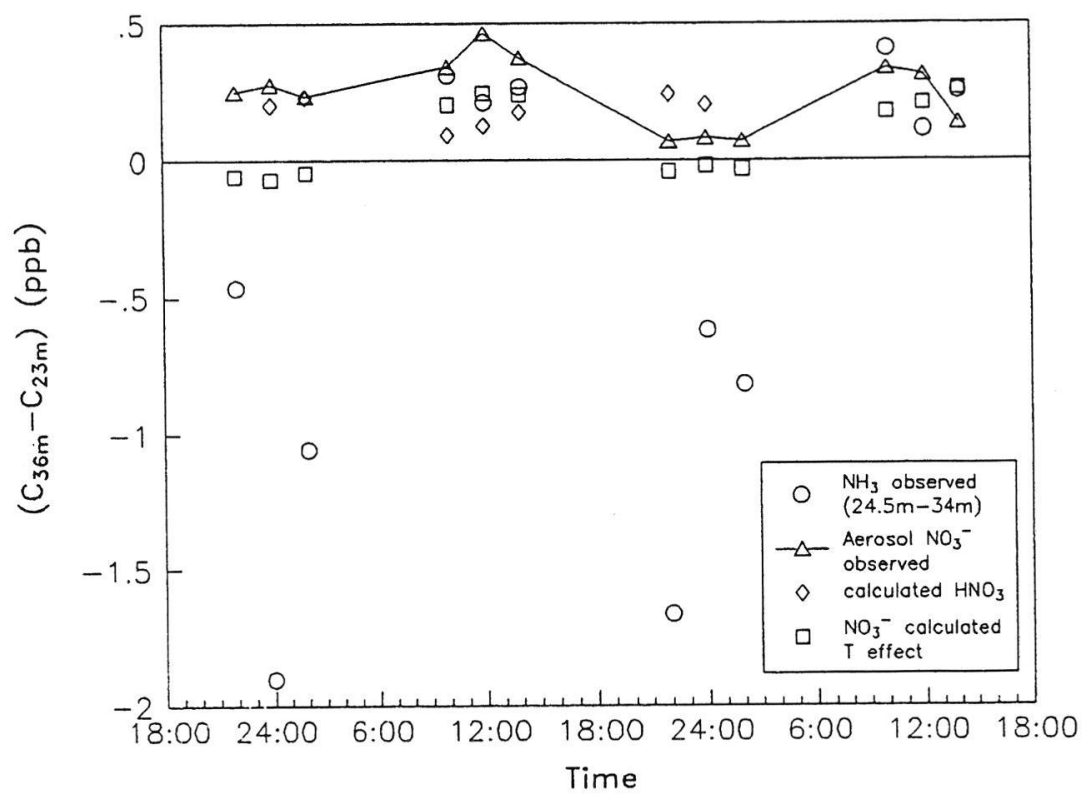

